\title{
Editorial
}

\section{ROBERT KIRKPATRICK}

Shinawatra International University, Thailand

This is the fourth and last issue of Language Testing in Asia for 2011. Our editorial board has expanded and now includes almost 20 members from various countries. However, the number of submissions is also increasing and more members are needed: recommendations for possible reviewers are most welcome.

In the first paper, Neda Karimi examines the applicability of C-test in vocabulary assessment. The study is conducted with the participation of Iranian TEFL MA students from Najaf Abad University. After analyzing the C-test results of 77 Students to investigate the effect of lexical variation and 74 students for that of lexical sophistication, she finds that their performance is significantly different in both situations. Her research paper points out that C-test has the potential to assess vocabulary knowledge, and finds that lexical measure is more suitable to be applied in the development of C-test.

A case study by Suchada Sanonguthai addresses effective ways to teach IELTS writing through English debate after looking at the performance of 20 Grade 12B students at a private school in Thailand. She reveals that a classroom debate is one of the most successful ways to train students to write better and think more critically through the three-hour class observation, after carrying out classroom observations, interviews with the debate coach and the students, and mock test results. She also shows that a debate 
activity in class encourages students to brainstorm, draft, write, feedback, revise and edit in a cyclical fashion.

The third paper, by Kamal Heidari Soureshjani, describes the influence of "time of administration" and "language of instruction" on the listening performance of Iranian EFL language learners. Altogether, 90 male and female students learning EFL from two well-known English language institutes in Shahrekord, Iran take part in the study and an old version of TOEFL test and listening comprehension test, which is derived from the material they are studying, is distributed among them at different times. He finds that when a listening test is given to the test takers in the morning, the scores of students are much better than when the same test is given to the same test takers at night. The study also shows that when a listening test is given with the instructions in the test takers' native language, their scores are far better than when the same test is given in target language instruction, English.

Thunyapat Witchukriangkrai discusses a comparison of teaching tense through texts and drills through a case study of grade 11 students of English program department of Assumption College Thonburi, Thailand. They are taught by two different teaching methods, using texts and drills and given pre-and post-tests, then the researcher looks at the advantages and disadvantages of the effects following from those teaching methods.

The last paper, entitled "An Evaluative Commentary of the Grade 1 EIKEN Test" investigates the fit between the "use" and "usefulness" of the Japan's Grade 1 EIKEN test as a valid and reliable instrument to measure 
second language proficiency. The researcher, Gabrielle Piggin, attempts to evaluate EIKEN test based on Bachman and Palmer's (1996) seminal model of test usefulness and suggests the need for future quantitative and qualitative analysis to justify EIKEN Grade 1's test usefulness. 